\title{
Gerenciamento de Lucros: que Pensam Administradores, Contadores e Outros Profissionais de Empresas no Brasil?
}

\author{
Moacir Sancovschi \\ Felipe Faissol Janot de Matos
}

\section{Resumo}

Este trabalho documenta e avalia os julgamentos de uma amostra de profissionais envolvidos com a administração de empresas no Brasil sobre gerenciamento de lucros, e os compara com os julgamentos de administradores, contadores e demais profissionais de empresas sediadas nos Estados Unidos. Um dos resultados mais importantes desse estudo é a constatação de que os entrevistados, em geral, consideraram eticamente aceitáveis as decisões operacionais tomadas para gerenciar lucros, e expressaram algumas reservas, mas não condenaram a adoção de práticas contábeis para cumprir a mesma finalidade. Outra constatação importante foi a de que os profissionais entrevistados nos Estados Unidos, quando comparados com os entrevistados no Brasil, discriminaram com maior clareza essas duas maneiras de gerenciar lucros. Sugeriu-se que esses resultados podem ser explicados pelos efeitos conjuntos (1) do uso generalizado de sistemas de controle financeiro nas empresas; (2) das características das normas que regem o funcionamento do mercado de capitais no Brasil e nos Estados Unidos; e (3) dos modos de governança corporativa das empresas que empregam os entrevistados. Este trabalho se encerra com algumas considerações críticas sobre duas propostas apresentadas para o controle do gerenciamento de lucros.

Palavras-chaves: gerenciamento de lucros; contabilidade; sistemas de controle gerencial; governança corporativa.

\begin{abstract}
In this study we surveyed 102 Brazilian managers about the morality of earnings management and compared their opinions with the opinions of 649 general managers and 265 accountants, surveyed in the U.S. We found that, in general, surveyed managers and accountants judged ethically acceptable taking operating decisions exclusively to meet short-term financial targets, but viewed as significantly less acceptable accomplishing the same ends by using accounting methods. Another important finding was that surveyed American managers, when compared to surveyed Brazilian managers, judged accounting manipulations more unethical, and operating manipulations more ethical means to manage earnings. We argue that this results from the combined effect of (1) widespread use of financial control systems to evaluate and reward managers; and (2) differences in corporate governance between American and Brazilian companies.
\end{abstract}

Key words: earnings management; accounting; management control systems; corporate governance. 


\section{INTRODUÇÃO}

O principal objetivo das demonstrações financeiras é fornecer, de maneira eficiente, informações relevantes sobre as atividades econômicas das organizações para todos aqueles que delas necessitam. A relevância dessas informações, nessa definição, depende, entre outras coisas, da capacidade que elas têm de representar, de refletir, as conseqüências financeiras das atividades econômicas sobre o patrimônio e os resultados das organizações.

Considerando que os princípios contábeis geralmente aceitos reúnem conceitos e técnicas que permitem representar com fidelidade as conseqüências financeiras das atividades econômicas sobre o patrimônio e os resultados das organizações, pode-se argumentar que para garantir a relevância das informações apresentadas nas demonstrações financeiras, administradores e contadores devem utilizar com competência os princípios contábeis geralmente aceitos, para elaborá-las.

Há casos, porém, em que administradores e contadores, pressionados a cumprir metas financeiras (lucro, retorno sobre o investimento, EVA, endividamento, liquidez, dividendos etc.) em condições em que as possibilidades de alcançá-las são reduzidas, e/ou em que os custos esperados de não atingi-las são considerados excessivos, eventualmente aproveitam a flexibilidade oferecida pelos princípios contábeis geralmente aceitos, com o propósito único e exclusivo de garantir que essas metas sejam atingidas. Na imprensa especializada, o uso impróprio da flexibilidade dos princípios contábeis para cumprir metas financeiras ou de lucro é denominado gerência de lucros. Consideram-se também como formas alternativas de gerenciamento de lucros as fraudes na preparação de demonstrações financeiras e as decisões tomadas exclusivamente para atingir objetivos de lucro.

O gerenciamento de lucros, por comprometer a qualidade das informações contidas nas demonstrações financeiras, interfere no processo de alocação de recursos na economia e inflige sérios prejuízos para diversos atores dos mercados de bens e serviços e de capitais. O Banco Nacional, no Brasil, e a Enron, nos Estados Unidos, são exemplos recentes de casos de gerenciamento de lucro que dispensam maiores comentários pelos danos que causaram às economias desses dois países. Não surpreende, portanto, a preocupação de legisladores, agentes fiscalizadores do mercado de capitais, administradores, analistas financeiros e pesquisadores com a conscientização de todos os 
envolvidos em atividades empresariais da seriedade do problema e com o controle do gerenciamento de lucros.

No Brasil, a evolução da legislação que rege o funcionamento das sociedades por ações e a Comissão de Valores Mobiliários, a instituição do Novo Mercado pela Bolsa de Valores de São Paulo, a atuação dos Conselhos Federal e Regionais de Contabilidade e a difusão da percepção, nos últimos anos, que o progresso profissional de administradores e contadores requer estudo continuado, fazem parte de um aparato que certamente contribui para aperfeiçoar as condições de governança corporativa das empresas que operam no país. Nesse cenário, tem-se dispensado especial atenção à natureza e à qualidade das informações apresentadas nas demonstrações financeiras, no pressuposto de que elas têm o potencial de interferir no julgamento de diferentes tomadores de decisão e direcionar o fluxo de recursos, financeiros ou não, para as atividades mais produtivas, tanto do ponto de vista de interessados particulares como da economia em geral. Ainda assim, não se pode excluir a possibilidade de que, eventualmente, gerentes e contadores respondam às pressões por resultados financeiros, gerenciando lucros. Por conseguinte, faz-se necessário desenvolver ampla compreensão das condições que incentivam e favorecem o gerenciamento de lucros, das maneiras como ele é perpetrado, das opiniões dos diferentes atores que participam do processo, e de como é possível reduzi-lo ao máximo, no caso de não se conseguir eliminá-lo. Somente ela permitirá que a sociedade se defenda dos efeitos negativos do gerenciamento de lucros.

Nos anos 90, quatro pesquisadores de universidades norte-americanas realizaram duas pesquisas que documentaram e avaliaram as opiniões de profissionais de empresas sobre o gerenciamento de lucros. Os referidos professores decidiram investigar as opiniões desses profissionais para registrar como eles se posicionavam em relação a questões técnicas com implicações éticas sérias, e para recolher informações que pudessem municiar as iniciativas de professores que planejassem integrar questões éticas nos cursos de Administração e Contabilidade, e de legisladores, de agentes fiscalizadores do mercado de capitais, de organizações empresariais que estivessem interessadas em desenvolver políticas, padrões e programas educacionais referentes ao gerenciamento de lucros.

A presente pesquisa replica e estende os estudos desses quatro professores. $\mathrm{O}$ seu principal objetivo é documentar e avaliar as opiniões de profissionais de empresas no Brasil sobre a gerência de lucros, e compará-las com as opiniões de profissionais de empresas entrevistados por esses pesquisadores. 
São cinco as seções que completam este artigo. Na segunda seção se descrevem as duas pesquisas realizadas nos Estados Unidos, nos anos 90, sobre gerenciamento de lucros. Na terceira se descrevem os métodos escolhidos para realizar esta pesquisa. Na quarta se documenta, analisa e compara as opiniões dos profissionais entrevistados no Brasil com as opiniões dos entrevistados nos Estados Unidos, e se propõem explicações para as opiniões emitidas pelos dois grupos de entrevistados. E, finalmente, na quinta seção apresentam-se as conclusões e comentários finais.

\section{ReVISÃo de Literatura}

O propósito dessa seção é comentar os resultados de duas pesquisas realizadas nos Estados Unidos, nos anos 90, que documentaram e avaliaram o julgamento de gerentes, supervisores, contadores e demais funcionários de empresas, sobre o gerenciamento de lucros, e enunciar os objetivos da presente pesquisa.

No início dos anos 90, os pesquisadores Bruns e Merchant (1989) submeteram aos leitores da Harvard Business Review um questionário com treze perguntas, para avaliar suas opiniões sobre gerenciamento de lucros ${ }^{(1)}$. Cada pergunta descrevia uma prática para o gerenciamento de lucros e solicitava que os leitores a julgassem, utilizando, para essa finalidade, uma escala de cinco pontos, assim designados: (1) Prática ética; (2) Prática questionável. Não mencionaria nada, mas me sentiria desconfortável; (3) Pequena infração. O gerente deve ser advertido para não repetir o procedimento; (4) Infração grave. O gerente deve ser severamente repreendido; (5) Totalmente antiético. O gerente deve ser demitido.

A análise das respostas dadas por 649 leitores revelou o elenco abaixo.

. Os julgamentos variaram consideravelmente. Nenhuma das 13 práticas foi unanimemente julgada como ética ou antiética.

. Em geral, os entrevistados consideraram que gerenciar lucros por meio de manipulações operacionais era mais ético do que gerenciar lucros por meio de manipulações contábeis.

- Gerenciar lucros para reduzi-los foi considerado mais aceitável do que gerenciar lucros para aumentá-los. 
- A materialidade influiu nos julgamentos. Gerenciar valores pequenos foi considerado mais aceitável do que gerenciar valores maiores.

- O período de tempo influiu nos julgamentos. Gerenciar lucros para atingir o orçamento do trimestre foi considerado mais aceitável do que gerenciar lucros para atingir a meta do exercício anual.

. O método proposto para gerenciar lucros influiu nos julgamentos. Aumentar lucros oferecendo condições de crédito atípicas foi considerado menos aceitável do que atingir o mesmo fim vendendo parte do ativo imobilizado excedente, ou recorrendo a horas extras para enviar o maior volume possível de mercadorias até o fim do exercício.

Interessados em saber se os entrevistados tinham consciência de que poderiam gerenciar lucros, caso desejassem, os pesquisadores reinquiriram alguns deles e observaram que a grande maioria usava, sem qualquer constrangimento, ao menos alguns métodos para a gerência de lucros. Concluíram que: (1) esses métodos eram inaceitáveis quando comparados com referencial ético adotado na pesquisa; e (2) embora esses métodos surtissem os efeitos desejados sobre os lucros reportados, os gerentes sabiam que eles não trariam benefícios econômicos reais para as empresas e, eventualmente, poderiam ser onerosos a longo prazo.

Preocupados com as conseqüências adversas do gerenciamento de lucros sobre a qualidade das demonstrações financeiras, Bruns e Merchant (1990) recomendaram que: (1) os administradores das empresas definissem padrões contábeis e operacionais mais claros e obrigassem todos a respeitá-los; (2) o controle das manipulações operacionais fosse delegado aos gerentes operacionais; e (3) se fomentasse nas empresas, e fora delas, uma cultura que valorizasse a administração para a excelência operacional, em vez de incentivar o alcance de objetivos quantitativos, financeiros ou não.

Fischer e Rosenzweig (1994) retomaram o estudo do gerenciamento de lucros, utilizando o questionário elaborado por Bruns e Merchant (1990) para avaliar a opinião de contadores sobre o gerenciamento de lucros. Eles justificaram a opção de focar a pesquisa nas opiniões dos contadores, baseados no fato de que esses profissionais podem influenciar os lucros reportados diretamente por meio da escolha de métodos contábeis, ou indiretamente, monitorando as decisões dos administradores.

Estes professores entrevistaram 265 integrantes de uma associação regional de contadores, nos Estados Unidos, representando, 
aproximadamente, $38 \%$ do número total de associados. As respostas que obtiveram foram semelhantes às obtidas por Bruns e Merchant (1990), como se pode observar a seguir.

- Os contadores julgaram o gerenciamento de lucros mediante escolha de métodos contábeis menos ético do que mediante decisões operacionais.

- As manipulações contábeis foram julgadas sérias ou moderadamente sérias, independentemente de envolverem avaliação de estoques ou não.

- Os contadores, em geral, não consideraram problemático o gerenciamento de lucros por meio de decisões operacionais. No entanto, julgaram as decisões operacionais que influenciam as despesas mais suspeitas do que aquelas que influenciam as receitas.

. Finalmente, comparando as opiniões dos contadores com o número de anos de experiência profissional e com a posição que ocupavam nas empresas, os pesquisadores constataram que a tolerância dos contadores ao gerenciamento de lucros por meio de decisões operacionais aumenta com a experiência profissional e com o nível de responsabilidade organizacional.

Fischer e Rosenzweig (1994), assim como Bruns e Merchant (1990), mostraramse preocupados com as implicações do gerenciamento de lucros para a qualidade das demonstrações financeiras. Para inibi-lo, recomendaram as seguintes medidas: (1) a realização de seminários para a sensibilização de administradores e contadores; (2) a revisão das normas de seleção e recrutamento de funcionários nas empresas; (3) a criação de códigos de ética nas empresas que contemplassem especificamente a escolha de normas contábeis e a tomada de decisões operacionais; e (4) a monitoração permanente das decisões operacionais nas empresas.

A presente investigação foi pautada nas pesquisas de Bruns e Merchant (1990) e Fischer e Rosenzweig (1994). Ela replicou os trabalhos desses pesquisadores e comparou os seus resultados com os encontrados nas pesquisas anteriores. Os objetivos dessa investigação são os seguintes: (1) documentar e avaliar os julgamentos de uma amostra de profissionais envolvidos com a administração de empresas no Brasil sobre o gerenciamento de lucros, e compará-los com os julgamentos dos entrevistados por Bruns e Merchant (1990) e Fischer e Rosenzweig (1994); e (2) propor uma possível explicação para o julgamento favorável demonstrado em relação às manipulações operacionais e para a relativa rejeição às manipulações contábeis. 


\section{Metodologia da Pesquisa}

Para documentar as opiniões de profissionais envolvidos com a administração de empresas no Brasil sobre gerenciamento de lucros, utilizou-se o questionário desenvolvido por Bruns e Merchant (1989). Ele foi traduzido e todos os valores nele incluídos foram expressos em Reais, de acordo com a cotação do dólar norte-americano no final de 2000.

O questionário descreve treze práticas para gerenciar lucros. Nele solicita-se que os entrevistados julguem cada prática escolhendo um ponto de uma escala de cinco pontos, assim designados: (1) Prática ética; (2) Prática questionável. Não mencionaria nada, mas me sentiria desconfortável; (3) Pequena infração. O gerente deve ser advertido para não repetir o procedimento; (4) Infração grave. O gerente deve ser severamente repreendido; (5) Totalmente antiética. O gerente deve ser demitido. Ao questionário, foram acrescentadas 10 perguntas que serviram para obter algumas informações sobre os profissionais entrevistados e as empresas que os empregam.

Por conveniência, decidiu-se entrevistar os participantes de cursos de pósgraduação lato sensu em Administração e Contabilidade, oferecidos por duas importantes instituições de ensino com sede na cidade do Rio de Janeiro, RJ. Em dezembro de 2000, foram enviados 300 questionários, dos quais 102 foram devolvidos corretamente preenchidos.

É necessário registrar que os profissionais entrevistados para esta pesquisa não foram selecionados de forma aleatória e, portanto, as estatísticas apresentadas a seguir servem apenas para descrever os seus julgamentos. Reproduz-se, dessa maneira, o mesmo procedimento adotado nas pesquisas anteriores para a seleção dos profissionais entrevistados.

Para viabilizar a comparação de resultados, utilizaram-se os mesmos métodos estatísticos usados nas pesquisas anteriores; são eles: (1) análise da freqüência relativa das respostas dos entrevistados nos cinco pontos da escala; e (2) análise das médias das opiniões dos entrevistados.

\section{Análise dos Resultados}

O objetivo dessa sessão é documentar e avaliar os julgamentos dos entrevistados, e compará-los com os julgamentos dos entrevistados nas pesquisas anteriores. 


\section{Descrição dos Entrevistados e das Empresas que os Empregam}

O Quadro 1 descreve o perfil dos entrevistados e algumas características das empresas que os empregam. Observa-se que 46\% deles trabalham há mais de 6 anos (a experiência profissional média é de 11 anos), todos têm curso superior completo, e 53\% são formados em Administração, Economia ou Contabilidade. Quanto as empresas que empregam os entrevistados, 51\% são de capital fechado e $72 \%$ de capital nacional.

\section{Quadro 1: Perfil dos Entrevistados e Características das Empresas que os Empregam}

\begin{tabular}{|l|l|l|l|}
\hline \multicolumn{2}{|l|}{ Formação Superior } & \multicolumn{2}{|l|}{ Experiência Profissional } \\
\hline Administração ou Economia & $30 \%$ & Até 6 anos & $48 \%$ \\
\hline Ciências Contábeis & $23 \%$ & Mais de 6 anos & $46 \%$ \\
\hline Engenharia & $17 \%$ & Não Responderam & $6 \%$ \\
\cline { 1 - 2 } Outras Formações & $30 \%$ & & \\
\cline { 1 - 2 } Natureza do Capital das Empresas & \multicolumn{2}{|l|}{ Origem do Capital das Empresas } \\
\hline Capital Aberto & $42 \%$ & Capital Nacional & $72 \%$ \\
\hline Capital Fechado & $51 \%$ & Capital Estrangeiro & $23 \%$ \\
\hline Não Responderam & $7 \%$ & Não Responderam & $5 \%$ \\
\hline
\end{tabular}

\section{Apresentação dos Resultados e Comparação com as Pesquisas Anteriores}

A Tabela 1 mostra as distribuições das opiniões dos profissionais entrevistados por Bruns e Merchant (1990), doravante denominado B\&M, e as distribuições das opiniões dos entrevistados nesta pesquisa (S\&M).

O item 1 revela que a direção do efeito das manipulações operacionais sobre o lucro afeta o julgamento dos entrevistados. Em ambas as pesquisas os entrevistados julgaram que manipulações operacionais que reduzem o lucro a curto prazo são mais éticas do que manipulações operacionais que aumentam o lucro. A tabela também demonstra que os entrevistados na pesquisa de B\&M foram mais tolerantes as manipulações operacionais do que os entrevistados no Brasil.

Comparando-se o item 1 com o item 2, observa-se que os entrevistados nos Estados Unidos e no Brasil consideraram as manipulações contábeis menos éticas do que as manipulações operacionais. O item 2 também demonstra que a materialidade interferiu no julgamento dos entrevistados por B\&M, mas não nos julgamentos dos entrevistados nesta pesquisa. Isto é, as manipulações contábeis 
de valores mais expressivos foram consideradas menos éticas do que as manipulações contábeis de montantes menores pelos entrevistados nos Estados Unidos; já a opinião dos entrevistados no Brasil não se modificou de maneira relevante, quando variaram os valores envolvidos nas manipulações. Finalmente, as distribuições das respostas ao item 2 comprovam que os profissionais entrevistados no Brasil mostraram-se mais tolerantes as manipulações contábeis que os entrevistados nos Estados Unidos.

Tabela 1: Comparação das Distribuições das Opiniões dos Entrevistados por Bruns e Merchant (1990) com as Distribuições das Opiniões dos Entrevistados nesta Pesquisa

\begin{tabular}{|c|c|c|c|c|c|c|}
\hline & \multicolumn{2}{|c|}{ Ética } & \multicolumn{2}{|c|}{$\begin{array}{l}\text { Questionável ou } \\
\text { Pequena Infração }\end{array}$} & \multicolumn{2}{|c|}{$\begin{array}{c}\text { Infração Grave } \\
\text { ou Antiética }\end{array}$} \\
\hline & $\mathrm{B} \& \mathrm{M}$ & S\&M & $\mathrm{B} \& \mathrm{M}$ & S\&M & $\mathrm{B} \& \mathrm{M}$ & S\&M \\
\hline $\begin{array}{l}\text { 1. Gerenciamento de lucros de curto prazo } \\
\text { por meio de mudanças de procedimentos/ } \\
\text { decisões operacionais }\end{array}$ & & & & & & \\
\hline Quando as mudanças reduzem o lucro & $79 \%$ & $53 \%$ & $19 \%$ & $39 \%$ & $2 \%$ & $8 \%$ \\
\hline Quando as mudanças aumentam o lucro & $57 \%$ & $39 \%$ & $31 \%$ & $45 \%$ & $12 \%$ & $16 \%$ \\
\hline $\begin{array}{l}\text { 2. Gerenciamento de lucros de curto prazo } \\
\text { por meio de manipulações ou mudanças } \\
\text { de procedimentos contábeis }\end{array}$ & & & & & & \\
\hline Quando os valores são pequenos & $5 \%$ & $11 \%$ & $45 \%$ & $58 \%$ & $50 \%$ & $31 \%$ \\
\hline Quando os valores são grandes & $3 \%$ & $14 \%$ & $21 \%$ & $56 \%$ & $76 \%$ & $30 \%$ \\
\hline $\begin{array}{l}\text { 3. Gerenciamento de lucros de curto prazo } \\
\text { via postergação de despesas } \\
\text { discricionárias para o próximo período } \\
\text { contábil }\end{array}$ & & & & & & \\
\hline Para cumprir o orçamento do trimestre & $47 \%$ & $29 \%$ & $41 \%$ & $55 \%$ & $12 \%$ & $16 \%$ \\
\hline Para cumprir o orçamento do ano & $41 \%$ & $23 \%$ & $35 \%$ & $58 \%$ & $24 \%$ & $20 \%$ \\
\hline $\begin{array}{l}\text { 4. Aumento de lucro à curto prazo para } \\
\text { cumprir meta orçamentária }\end{array}$ & & & & & & \\
\hline $\begin{array}{l}\text { Mediante venda de ativos excedentes para } \\
\text { melhorar o resultado }\end{array}$ & $80 \%$ & $54 \%$ & $16 \%$ & $35 \%$ & $4 \%$ & $11 \%$ \\
\hline $\begin{array}{l}\text { Mediante utilização de horas extras para } \\
\text { enviar o máximo possível de mercadorias }\end{array}$ & $74 \%$ & $52 \%$ & $21 \%$ & $36 \%$ & $5 \%$ & $12 \%$ \\
\hline $\begin{array}{l}\text { Mediante oferecimento de descontos e } \\
\text { créditos para garantir a venda de } \\
\text { mercadorias }\end{array}$ & $43 \%$ & $36 \%$ & $44 \%$ & $39 \%$ & $15 \%$ & $25 \%$ \\
\hline
\end{tabular}

O item 3 mostra que o período de tempo em que ocorrem os efeitos das manipulações afeta o julgamento dos entrevistados. Em geral, o adiamento de despesas discricionárias para cumprir as metas orçamentárias de um trimestre foi considerado menos grave que o adiamento para cumprir as metas orçamentárias de um ano. Mais uma vez, os entrevistados nos Estados Unidos se mostraram mais tolerantes a esse tipo de manipulação operacional que os entrevistados no Brasil. 
No item 4 observa-se que o método usado para gerenciar lucros a curto prazo interfere no julgamento dos entrevistados. Das alternativas fornecidas, os entrevistados consideraram que a venda de ativos excedentes e a contratação de horas extras para maximizar o volume de vendas são, nesta ordem, meios mais éticos para cumprir metas de resultado a curto prazo do que o oferecimento de condições especiais aos clientes para fechar negócios que de outra forma não seriam realizados. Novamente, os entrevistados nos Estados Unidos assumiram posição mais tolerante que os entrevistados nos Brasil.

A Tabela 2 compara as médias das opiniões dos contadores entrevistados por Fischer e Rosenzweig (1994), doravante denominado F\&R, com as médias das opiniões dos contadores entrevistados para esta pesquisa (S\&M).

Tabela 2: Comparação das Médias das Opiniões dos Contadores Entrevistados por Fischer e Rosenzweig (1994) com as Médias das Opiniões dos Contadores Entrevistados nesta Pesquisa, Classificadas de acordo com o Tipo de Manipulação para Gerenciar Lucros

\begin{tabular}{|c|c|c|c|c|c|}
\hline & \multirow{2}{*}{ Fator } & \multicolumn{2}{|c|}{ Média } & \multicolumn{2}{|c|}{ Média do Fator } \\
\hline & & F\&R & S\&M & $\mathbf{F \& R}$ & S\&M \\
\hline \multirow{5}{*}{ Manipulações Contábeis } & $\begin{array}{l}\text { Avaliação de } \\
\text { Estoques }\end{array}$ & $\begin{array}{l}3,32 \\
3,50 \\
371\end{array}$ & $\begin{array}{l}3,17 \\
2,83\end{array}$ & 3,51 & 2,97 \\
\hline & & 3,29 & 3,35 & & \\
\hline & Outras & 3,27 & 2,61 & 3,49 & 2,97 \\
\hline & Gitias & 3,24 & 2,78 & & \\
\hline & & 4,15 & 3,13 & & \\
\hline \multirow{6}{*}{$\begin{array}{l}\text { Manipulações } \\
\text { Operacionais }\end{array}$} & & 1,18 & 2,00 & & \\
\hline & Despesas & 1,62 & 2,00 & 1,56 & 2,16 \\
\hline & & 1,88 & 2,48 & & \\
\hline & & 1,81 & 1,91 & & \\
\hline & Receitas & 1,30 & 1,65 & 1,45 & 1,94 \\
\hline & & 1,25 & 2,26 & & \\
\hline
\end{tabular}

Nota: (1) Ética; (2) Questionável; (3) Pequena Infração; (4) Infração Grave; (5) Antiética.

A tabela demonstra que os contadores entrevistados no Brasil e nos Estados Unidos consideraram as manipulações contábeis menos éticas do que as manipulações operacionais. Mais importante que esta coincidência, é a maneira como ela se apresenta. As médias das opiniões dos contadores entrevistados nos Estados Unidos denotam que eles discriminaram com mais clareza as manipulações contábeis das manipulações operacionais e julgaram as primeiras mais problemáticas que as últimas.

Diferentemente, as médias das opiniões dos contadores entrevistados no Brasil demonstram que eles não discriminaram de forma relevante as 
manipulações contábeis das manipulações operacionais, e que eles são mais tolerantes em relação a gerência de lucros mediante manipulações contábeis que os contadores entrevistados nos Estados Unidos. No entanto, eles se mostraram mais severos quando julgaram a gerência de lucros mediante decisões operacionais.

\section{Análise dos Resultados}

Após analisar os julgamentos dos profissionais entrevistados no Brasil sobre a gerência de lucros, e compará-los com os julgamentos dos profissionais entrevistados nos Estados Unidos, em duas oportunidades distintas, pode-se fazer algumas constatações.

A primeira é que nas três pesquisas nenhuma prática foi unanimemente julgada como ética ou antiética. Em geral, as opiniões variaram bastante, independente da prática envolver manipulação contábil ou operacional e aumentar ou diminuir o lucro. Esse resultado pode ser atribuído ao fato de que a Administração e a Contabilidade não se inserem no campo das ciências exatas. A liberdade para avaliar e decidir é, e sempre será, fundamental para o adequado desempenho dessas atividades.

A segunda constatação é que nas três pesquisas os entrevistados julgaram a gerência de lucros mediante decisões operacionais mais ética do que mediante adoção de práticas contábeis. No entanto, os profissionais entrevistados nos Estados Unidos mostraram-se mais tolerantes as manipulações operacionais do que os profissionais entrevistados no Brasil.

Pode-se argumentar que as opiniões emitidas em relação ao recurso a decisões operacionais para alcançar objetivos de lucro sejam fortemente influenciadas pelo uso generalizado, no Brasil e nos Estados Unidos, de sistemas de controle financeiro para avaliar o desempenho dos gerentes e das unidades pelas quais eles são responsáveis ${ }^{(2)}$. Não obstante a existência de propostas alternativas (Eccles, 1991; Kaplan e Norton, 1992), o sucesso de administradores e de empresas ainda é medido em função do lucro auferido em intervalos de tempo menores ou iguais a um ano (Eccles e Mavrinac, 1995; Ittner, Larcker e Rajan, 1997). Portanto não surpreende que grande parte dos envolvidos com a administração de empresas julgue legítimas as decisões operacionais que contribuam para o alcance dos objetivos de lucro de curto prazo.

Parfet (2000), que é executivo de uma empresa nos Estados Unidos, ilustra com bastante clareza o sentimento geral dos executivos em relação às manipulações operacionais. Diferente da opinião dos acadêmicos, ele afirma que 
existe gerenciamento benigno de lucros, que consiste em tomadas de decisões operacionais para garantir o cumprimento de metas de lucro, tais como a venda de equipamentos ou o oferecimento de descontos para antecipar transações que ocorreriam normalmente no período seguinte, quando o lucro estiver abaixo do esperado. Na sua concepção, alcançar resultados estáveis e previsíveis e manter a taxa de crescimento dos lucros por meio de bom planejamento e resposta operacional, não é ilegal ou antiético. É sinal de habilidade e excelência que o mercado procura e recompensa ${ }^{(3)}$.

Bhide $(1993,1994)$ fornece uma possível explicação para o uso difundido de sistemas de controle financeiro nos Estados Unidos e para a opinião favorável dos profissionais entrevistados por B\&M e por F\&R em relação a tomada de decisões operacionais para alcançar objetivos de lucro. Segundo ele, as normas adotadas para proteger os investidores e garantir a alta liquidez do mercado de ações, formalizaram demasiadamente as relações entre investidores e administradores, e privilegiaram as demonstrações financeiras como meio de comunicação entre investidores e administradores ${ }^{(4)}$. Assim as atenções de todos os atores do mercado concentraram-se nos indicadores financeiros de desempenho. Eventualmente, ele lembra, a valorização desmedida do desempenho financeiro submete a economia norte-americana a custos de diversos tipos. Chastain (1980) destaca que o uso excessivo de medidas financeiras de curto prazo reduziu o horizonte de tempo dos gerentes norteamericanos; Hayes e Abernathy (1980) atribuíram a perda de competitividade das empresas norte-americanas na década de 70, entre outros fatores, ao uso difundido de medidas financeiras de curto prazo para avaliar o desempenho das empresas.

Os trabalhos de Bhide $(1993,1994)$ também oferecem uma explicação para a opinião menos favorável dos profissionais entrevistados no Brasil sobre a gerência de lucros mediante decisões operacionais. Ele afirma que em países onde o mercado de ações é menos regulamentado, os investidores são menos protegidos e a liquidez dos investimentos é menor, em geral os investidores tendem a participar ativamente da administração das empresas, as relações entre investidores e administradores tornam-se menos formalizadas, e a utilização de indicadores financeiros para a avaliação de desempenho tornase menos importante. Nesse cenário, atingir metas de lucro em curto prazo não é condição suficiente para o sucesso de uma empresa ou de um administrador, especialmente se isso for feito em detrimento de resultados de longo prazo.

Esta realmente parece ser a situação das empresas que empregam os entrevistados nesta pesquisa. Conforme relatado anteriormente, $51 \%$ dos 
entrevistados eram funcionários de empresas de capital fechado, e $42 \%$ eram funcionários de empresas de capital aberto. Porém, mesmo no caso de empresas de capital aberto, é comum no Brasil que a propriedade esteja concentrada na mão de um reduzido número de investidores, que usualmente participa de forma ativa da administração dessas empresas ${ }^{(5)}$. Espera-se, nesse caso, que a avaliação de administradores e de unidades leve em conta outros fatores, além dos resultados financeiros de curto prazo.

A terceira constatação é que os entrevistados nos Estados Unidos e no Brasil se mostraram relativamente severos quando avaliaram as situações que descreviam a gerência de lucros mediante adoção de práticas contábeis. Parece que todos estavam conscientes que estas manipulações representam distorções deliberadas de fatos ocorridos.

Recorrendo-se, novamente, à avaliação que Bhide $(1993,1994)$ faz das normas que regem o funcionamento do mercado de ações nos Estados Unidos, pode-se entender a posição mais extremada dos entrevistados naquele país em relação às manipulações contábeis e, também, o fato deles discriminarem com mais clareza essas manipulações das manipulações operacionais. Parece não haver dúvida, para os entrevistados nos Estados Unidos, que a gerência de lucros mediante decisões operacionais é um problema que tem que ser resolvido entre administradores, investidores e demais interessados numa empresa específica. No entanto, eles são constantemente lembrados que a gerência de lucros mediante adoção de procedimentos contábeis, por comprometer a credibilidade do mercado de ações, expõe os envolvidos não só a processos movidos por investidores, como também às sanções dos agentes que fiscalizam o funcionamento do mercado de ações. E lá essas sanções são severas ${ }^{(6)}$. Loomis (1999) relatou casos recentes de gerência fraudulenta de lucros, que geraram severas penalidades aos seus responsáveis.

Os entrevistados no Brasil, talvez por serem, em sua maioria, funcionários de empresas de capital fechado e/ou concentrado, foram relativamente menos rigorosos no julgamento das manipulações contábeis e as discriminaram menos em relação às manipulações operacionais que os entrevistados nos Estados Unidos.

Um aspecto digno de nota é que as observações feitas anteriormente podem ser consideradas generalizáveis. Embora os autores desta pesquisa e das pesquisas anteriores não tenham selecionado aleatoriamente seus entrevistados, certos resultados se repetiram da mesma forma nas três pesquisas, o que sugere que são grandes as chances de que sejam sistemáticos. 


\section{Conclusões}

A presente investigação replicou as pesquisas de Bruns e Merchant (1990) e Fischer e Rosenzweig (1994). Ela teve dois objetivos. O primeiro foi documentar e avaliar os julgamentos de uma amostra de profissionais envolvidos com a administração de empresas no Brasil sobre o gerenciamento de lucros, e compará-los com os julgamentos de administradores, contadores e demais profissionais de empresas sediadas nos Estados Unidos, entrevistados por esses pesquisadores. O segundo foi propor uma possível explicação para o julgamento favorável em relação às manipulações operacionais e para a relativa rejeição às manipulações contábeis. A seguir são resumidas as principais conclusões deste trabalho.

Em geral, os resultados encontrados nesta e nas demais pesquisas foram convergentes. Eles demonstraram o que se lista abaixo.

. Os julgamentos variaram consideravelmente. Nenhuma das 13 práticas foi julgada unanimemente ética ou antiética.

. Os entrevistados, em média, julgaram éticas ou, na pior das hipóteses, questionáveis, as decisões operacionais tomadas com o propósito de alcançar metas de lucro de curto prazo. A expressão "gerenciamento benigno de lucros”, usada por Parfet (2000), parece resumir com propriedade o sentimento dos entrevistados em relação às manipulações operacionais.

. Os entrevistados, em média, julgaram a escolha de práticas contábeis para alcançar metas de lucro como questionáveis ou, no máximo, infrações graves. Isto é, as manipulações contábeis foram consideradas condenáveis, porém não antiéticas.

. Os entrevistados consideraram que gerenciar lucros mediante a tomada de decisões operacionais é eticamente mais aceitável do que gerenciá-los mediante a escolha de procedimentos contábeis específicos.

Por outro lado, deve-se registrar que, embora convergentes, os julgamentos exibiram variações que talvez possam ser atribuídas às diferenças existentes entre os regulamentos que regem o funcionamento do mercado de capitais nos Estados Unidos e no Brasil, e/ou às diferenças nos modos de governança corporativa das empresas que empregam os entrevistados em ambos os países. Elas são apresentadas a seguir. 
. Os entrevistados nos Estados Unidos mostraram-se mais tolerantes ao uso de decisões operacionais para alcançar metas de lucro do que os entrevistados no Brasil.

. Os entrevistados nos Estados Unidos julgaram com mais severidade a escolha de procedimentos contábeis com o propósito de cumprir metas de lucro do que os entrevistados no Brasil.

. Os contadores entrevistados nos Estados Unidos discriminaram com mais clareza as manipulações contábeis das manipulações operacionais do que os contadores entrevistados no Brasil.

O segundo objetivo desta pesquisa foi propor uma possível explicação para o julgamento favorável exibido em relação às manipulações operacionais e para a relativa rejeição às manipulações contábeis. Nesse aspecto, argumentou-se, primeiramente, que a tomada de decisões operacionais para cumprir metas de lucro é induzida e, portanto, legitimada pelo uso generalizado de sistemas de controle financeiro, tanto nas empresas norte-americanas como nas brasileiras. Os efeitos desses sistemas são potencializados, no caso das empresas sediadas nos Estados Unidos, por força de um ambiente institucional que incentiva a dispersão da propriedade das empresas e uma relação distante e formal entre administradores e acionistas, na qual as demonstrações financeiras se constituem em importante meio de comunicação. No Brasil, ao contrário, os efeitos dos sistemas de controle financeiro são grandemente amortecidos pela força da concentração da propriedade das empresas, mesmo naquelas de capital aberto, que obriga os acionistas a participarem ativamente na administração de suas empresas. Se eventualmente essas decisões ameaçam o futuro das empresas e do patrimônio dos investidores, é necessário que os sistemas de controle sejam revistos para privilegiar objetivos distintos de resultados financeiros de curto prazo. Existem evidências de que administradores esclarecidos procedem essas revisões. Ittner, Larcker e Rajan (1997) verificaram que o uso formal de medidas nãofinanceiras nos contratos de bonificação de CEO's, nos Estados Unidos, cresce com a adoção de estratégias orientadas para inovação e qualidade, e com a presença de ruídos exógenos nas medidas financeiras.

A escolha de procedimentos contábeis com o propósito explícito de cumprir objetivos de lucro, por distorcer a realidade, é tida como desvio de conduta em qualquer parte do mundo civilizado. No entanto, deve-se considerar que as suas conseqüências dependem da importância relativa do papel desempenhado pelas demonstrações financeiras no cenário institucional. Pode-se sugerir, portanto, que o grau de rejeição às manipulações contábeis para gerenciar lucros seja influenciado pela severidade dos efeitos que elas podem trazer para todos 
os atores do mercado. Nos Estados Unidos, a dispersão da propriedade das empresas e a formalização das relações entre acionistas e administradores confere às demonstrações financeiras a função de um dos principais meios de comunicação entre administradores e acionistas. O adequado desempenho dessa função está baseado na confiança que todos depositam nas informações que elas trazem, nos contadores e administradores que as elaboram e nos auditores que as certificam. Qualquer problema que comprometa essa confiança representa sério risco para o funcionamento do mercado. É por esse motivo que, nos Estados Unidos, as intervenções dos agentes que fiscalizam o funcionamento do mercado de capitais para preservar a qualidade das demonstrações financeiras, são geralmente rápidas, severas e fartamente veiculadas nos meios de comunicação; administradores, contadores e auditores assumem uma posição especialmente crítica em relação às manipulações contábeis.

Diferentemente, no Brasil, onde a propriedade das empresas é concentrada e os acionistas participam ativamente da administração de suas empresas, os incentivos para adoção de práticas contábeis para alcançar objetivos de lucro são menores, as conseqüências dessas manipulações são menos percebidas, a atuação dos agentes que fiscalizam o mercado de capitais é menos visível, e os participantes são menos críticos em relação a elas. Contudo, isso não significa que elas não existam, não sejam significativas, não causem prejuízos para os envolvidos ou que sejam ignoradas. Simplesmente aqui, em função das características do cenário institucional, as manipulações contábeis, em geral, não recebem o destaque que a elas é conferido nos Estados Unidos.

Por fim, cabe avaliar as propostas sugeridas nas pesquisas anteriores para minimizar o gerenciamento de lucros. No entanto, em primeiro lugar, é preciso destacar que não obstante os entrevistados nas três pesquisas terem julgado com mais rigor a adoção de práticas contábeis do que a tomada de decisões operacionais para atingir objetivos de lucro, percebe-se que o grau de desaprovação foi relativamente reduzido. Esse resultado talvez seja explicado, em parte, por problemas na construção do questionário, pela forma como ele foi submetido aos entrevistados, e pelo cuidado que eles tiveram ao respondêlo. Todavia, mesmo imperfeito, ele sugere que é necessária a criação e manutenção de mecanismos e incentivos para resguardar a qualidade das informações apresentadas nas demonstrações financeiras, sob pena de se colocar em risco um importante canal de comunicação, especialmente no caso de empresas de grande porte e descentralizadas, entre administradores, investidores, instituições financeiras, agentes do governo e demais interessados nos resultados das empresas. 
Destarte, a questão que se apresenta é que mecanismos e incentivos devem ser usados para garantir a qualidade das informações constantes das demonstrações financeiras. Bruns e Merchant (1990) recomendaram (1) que os administradores das empresas definissem padrões contábeis e operacionais mais claros e obrigassem todos a respeitá-los; (2) que o controle das manipulações operacionais fosse delegado aos gerentes operacionais; e (3) que se fomentasse nas empresas, e fora delas, uma cultura que valorizasse a administração para a excelência operacional em vez de incentivar o alcance de objetivos quantitativos, financeiros ou não. Fischer e Rosenzweig (1994), propuseram (1) a realização de seminários para a sensibilização de administradores e contadores; (2) a revisão das normas de seleção e recrutamento de funcionários nas empresas; (3) a criação de códigos de ética nas empresas que contemplassem especificamente a escolha de normas contábeis e a tomada de decisões operacionais; e (4) a monitoração permanente das decisões operacionais nas empresas.

Avaliando-se as referidas recomendações, percebe-se que elas não diferenciam, como deveriam, as manipulações contábeis das manipulações operacionais. Pode-se argumentar que decisões operacionais tomadas para garantir o alcance de objetivos de lucro de curto prazo que causem prejuízo às empresas, devem ser evitadas, principalmente no âmbito das empresas, por meio da implantação de sistemas de controle apropriados. Para isso talvez seja necessário (1) definir padrões operacionais claros e obrigar todos a respeitálos; (2) responsabilizar os gerentes operacionais pelas decisões que tomam; (3) contratar gerentes operacionais competentes e com elevado senso ético; (4) implantar códigos de ética; (5) investir na capacitação permanente de gerentes e demais funcionários; e (6) fomentar uma cultura que valorize o desempenho competente das tarefas e não a manutenção de um conjunto de indicadores dentro de limites aceitáveis.

Diferentemente, as escolhas de práticas contábeis para cumprir objetivos de lucro representam desvios de conduta de administradores, contadores e auditores, que prejudicam tanto os interessados em empresas específicas, como os demais participantes do mercado de capitais. Portanto, elas devem ser evitadas institucionalmente, por meio de permanente avaliação das normas que regem a elaboração das demonstrações financeiras, pela implantação e manutenção de normas de conduta que estabeleçam os direitos e responsabilidades de todos os participantes do mercado de ações, e de mecanismos de arbitragem para dirimir dúvidas, acertar disputas entre participantes e punir os transgressores; e, no âmbito das empresas, por meio da implantação de sistemas de controle apropriados, tal como indicado anteriormente. É oportuno lembrar que o aparato normativo e coercitivo do 
mercado exercerá forte influência nas características dos sistemas de controle adotados pelas empresas que, certamente, deve ser objeto de análise cuidadosa, para não impor ao sistema como um todo custos que excedam os benefícios esperados.

\section{Notas}

${ }^{1}$ Os referidos autores assumiram, sem maiores considerações, que: (1) a essência de uma abordagem moral ou ética para a administração é preservar o equilíbrio entre os interesses e obrigações de todos aqueles que participam das atividades de uma empresa (administradores, funcionários, clientes, fornecedores, acionistas, financiadores etc.); e (2) o gerenciamento de lucros consiste na adoção de práticas contábeis ou na tomada de decisões operacionais com o propósito único e exclusivo de alcançar um objetivo de lucro num dado período de tempo, não importando como, nem por quem, ele tenha sido determinado.

${ }^{2}$ Merchant (1990) documentou, por meio de um estudo em duas empresas norte-americanas e de entrevista com 54 gerentes divisionais de uma dessas empresas, que, quando pressionados a cumprir metas de lucro líquido ou orçamentos de despesas/custos, os gerentes eventualmente antecipam a realização do lucro dos períodos seguintes, postergando despesas e antecipando receitas. O controller de uma das empresas estudadas justificou o comportamento dos gerentes de sua empresa observando que os planos precisam ser ajustados às condições do mercado e que se um gerente não consegue fazer correções no desempenho de curto prazo também não conseguirá fazê-lo no longo prazo. Bushee (1998) estudou o comportamento de 13.944 empresas/ ano no período 1983-1994 e observou (1) que a probabilidade dos gerentes cortarem gastos com pesquisa e desenvolvimento para reverter uma redução nos lucros, diminui quando a participação de investidores institucionais (companhias seguradoras, fundos mútuos ou de pensão etc.) no capital de suas empresas é elevada, demonstrando que esses investidores contribuem para reduzir as pressões para os gerentes assumirem um comportamento míope em relação a investimentos de longo prazo; e (2) que essa probabilidade aumenta de forma significativa quando investidores institucionais com carteiras de investimento de alto giro e operações especulativas detém parcela elevada do capital das empresas. Jensen (2001) atribui à vinculação de parcela significativa da remuneração dos executivos ao cumprimento de metas orçamentárias, o fato de, eventualmente, eles tomarem decisões e agirem de forma a destruir o valor das empresas que os empregam.

${ }^{3}$ Parfet (2000), na defesa de sua posição como administrador, esquece que a diferença entre um remédio e um veneno está, muitas vezes, na dose ou nas circunstâncias em que ele é utilizado. Maremot (1993) relata o caso da Bausch \& Lomb, onde executivos pressionados a alcançar metas de lucro excessivamente ambiciosas, tomaram decisões operacionais que geraram os lucros esperados a curto prazo; porém, a longo prazo, infligiram severos prejuízos a empresa e aos seus investidores.

${ }^{4}$ Jensen (1989) também afirma que as leis e regulamentos que regem o funcionamento do mercado de capitais nos Estados Unidos, que datam da época da Grande Depressão, criaram uma intrincada rede de restrições para administradores e investidores que detenham mais que $10 \%$ das ações com direito a voto, restrições para o envolvimento dos bancos nas restruturações corporativas, jurisprudências e práticas empresariais, que elevaram excessivamente os custos dos investidores participarem ativamente na administração de suas empresas. Dessa forma, incentivaram a dispersão 
da propriedade das empresas de capital aberto e o estabelecimento de relações distantes e formais entre acionistas e administradores.

${ }^{5}$ Gouvêa, Laouchez e Lindenboim (2002) afirmaram que a propriedade de uma companhia brasileira, em média, está concentrada nas mãos de três acionistas que detêm, entre eles, 85\% das ações com direito a voto. Nela, os proprietários são usualmente diretores e administradores. Eles consultaram 127 participantes dos conselhos de 74 empresas brasileiras e constataram, entre outras coisas, que os conselhos freqüentemente existem para atender os requisitos da legislação vigente no país, que somente $66 \%$ dos entrevistados analisam relatórios e projetos antes das reuniões, e que as decisões dos conselhos raramente são influenciadas pelos acionistas minoritários. Os entrevistados, em sua maioria, mostraram-se satisfeitos com o atual baixo nível de abertura de informações para o mercado financeiro e com o modelo de governança corporativa de suas empresas. A título de ilustração, também vale apresentar algumas informações sobre a concentração da propriedade das empresas de capital aberto no Brasil. Siqueira (1998) selecionou uma amostra de 278 empresas de capital aberto com informações disponíveis na base de dados da Economática, e observou que em $68 \%$ das empresas, o principal acionista detinha mais de $50 \%$ das ações com direto a voto, em $25 \%$ das empresas o principal acionista detinha entre $20 \%$ e $50 \%$ do capital com direito a voto, e em $7 \%$ das empresas o principal acionista detinha até $20 \%$ das ações com direito a voto. Siffert Filho (1998) estudou as mudanças no controle acionário das 100 maiores empresas não financeiras na economia brasileira no período 1990-1997. Ele observou que em 1990, considerando as 100 maiores empresas, em uma a propriedade era dispersa, em cinco a propriedade era dominante, e em 88 a propriedade era majoritária (propriedade familiar, governamental ou estrangeira); em 1997, o número de empresas com propriedade dispersa cresceu para três, com propriedade dominante cresceu para 19, e com propriedade majoritária reduziu para 77.

${ }^{6}$ Luciana Rodrigues, em matéria publicada no caderno Economia do jornal O Globo (2002, p.31) afirmou: "se fosse no Brasil, o escândalo da Enron provavelmente seria mais um caso em que os grandes fraudadores escapam da prisão. Advogados especializados em mercados de capitais explicam que, tal como nos EUA, a legislação brasileira é severa e prevê pesadas sanções a quem prejudica os investidores de companhias negociadas em bolsa. A diferença é que aqui os processos se arrastam por anos e os acusados dificilmente vão para a cadeia”.

\section{REFERÊNCIAS Biblográficas}

\section{BHIDE, A.}

The hidden costs of stock market liquidity. Journal of Financial Economics, n. 34, p. 31-51, 1993.

\section{Efficient markets, deficient} governance. Harvard Business Review, p. 128-139, Nov./Dec. 1994.
BRUNS, W.;

MERCHANT, K.

Ethics test for everyday managers.

Harvard Business Review, p. 220-221, Mar./Apr. 1989.

The dangerous morality of managing earnings. Management Accounting, p. 21-25, Aug. 1990. 
BUSHEE, B.

The influence of institutional investors on myopic R\&D investment behavior. The Accounting Review, v. 73, n. 3, July 1998.

CHASTAIN, C.

Management's increasing dependence on accounting measures. Management International Review, v. 20-24, p. 83-93, 1980.

ECCLES, R. G.

The performance measurement manifesto. Harvard Business Review, v. 69, n. 1, p. 131-137, Jan./Feb. 1991.

ECCLES, R.;

MAVRINAC, S.

Improving the corporate disclosure process. Sloan Management Review, v. 36, n. 4, p. 11-25, Summer 1995.

FISCHER, M.; ROSENZWEIG, K.

Is managing earnings ethically acceptable? Management Accounting, v. 75, n. 9, p. 31-34, Mar. 1994.

GOUVÊA, A.; LAOUCHEZ, J.;

LINDEBOIM, P.

Brazilian boardrooms. The MacKinsey Quarterly, n. 2, 2002.
HAYES, R.;

ABERNATHY, W.

Managing our way to economic decline. Harvard Business

Review, p. 67-77, July/Aug. 1980.

HEALY, P.;

WAHLEN, J.

A review of the earnings management literature and its implications for standard setting. Accounting Horizons, v. 13, n. 4, p. 365-383, Dec. 1999.

ITTNER, C.;

LARCKER, D.;

RAJAN, M.

The choice of performance measures in annual bonus contracts. The Accounting Review, v. 72, n. 2, p. 231-255, Apr. 1997.

JENSEN, M.

Eclipse of the public corporation. Harvard Business Review, v. 67, n. 5, p. 61-74, Sept./Oct. 1989.

Corporate budgeting is broken: let's fix it. Harvard Business Review, p. 95-101, Nov. 2001.

KAPLAN, R.;

NORTON, D.

The balanced scorecard: measures that drive performance. Harvard Business Review, v. 70, p. 7179, Jan./Feb. 1992. 
LOOMIS, C.

Lies, damned lies, and managed earnings. Fortune, p. 86-95, Aug. 1999.

MERCHANT, K.

The effects of financial controls on data manipulation and management myopia.

Accounting, Organizations and Society, v. 15, n. 4, p. 297-313, 1990.

MAREMOT, M.

Blind ambition: how the pursuit of results got out of hand at Bausch
\& Lomb. Business Week, p.4656, Oct. 1995.

PARFET, W.

Accounting subjectivity and earnings management: a preparer perspective.

Accounting

Horizons, v. 14, n. 4, p. 481-488, Dec. 2000.

SATHE, V.

The controller's role in management. Organizational Dynamics, v. 11, n. 3, p. 31-48, Winter 1983. 